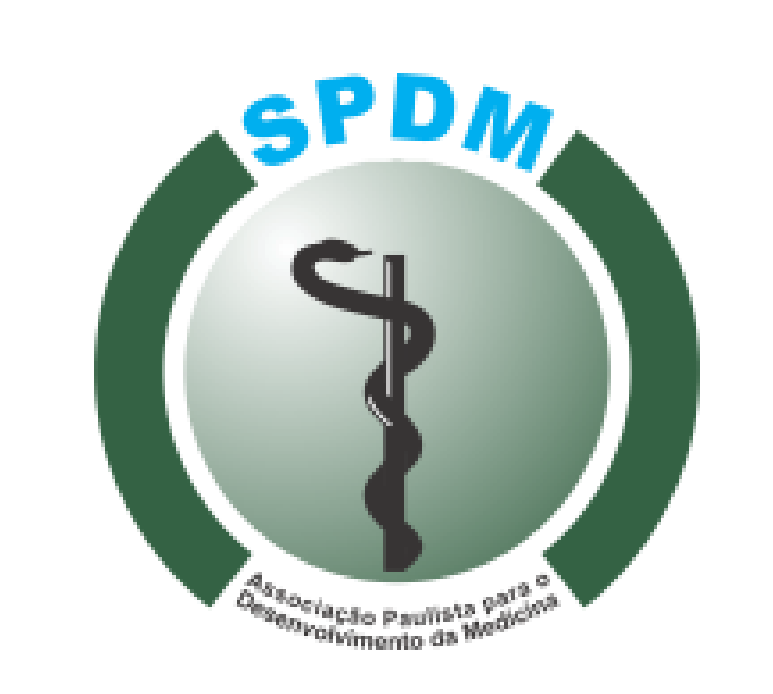

\title{
Retrospectiva do ano de 2017 dos pacientes Trombolisados na Linha de Cuidados (LC) de Acidente Vascular Encefálico Isquêmico (AVEi) em um Hospital Municipal de São José dos Campos
}

Eixo temático: Avaliação e Qualidade do Cuidado

Introdução: O AVEi está entre uma das maiores causas de mortalidade e morbidade mundial, comprometendo boa parte da população economicamente ativa. Estima-se que é a primeira causa de incapacidade física no mundo. Em uma expectativa para diminuir danos ao paciente, como tratamento na fase aguda do AVEi é realizada a trombólise endovenosa com o ativador plasminogênico tecidual (rt-PA), que utilizado em até 4,5h do início dos sintomas proporciona melhora dos déficits em até 180 dias da administração. ${ }^{1-2}$

Objetivo: Descrever o acompanhamento do paciente 180 dias pós trombólise acompanhados via ambulatorial através da escala de National Institute of Health Stroke Scale (NIHSS).

Metodologia: Análise retrospectiva, quantitativa referente ao banco de dados da LC ao paciente com AVEi (LCAVE) do HMJCF, referente ao ano de 2017.

Resultados: Foram realizadas 24 trombólises no ano de 2017. A média de idade foi 63 anos (40-84 anos), $71 \%$ eram homens. O tempo médio do início dos sintomas até o tratamento com rtPA foi de 184 minutos. O tempo porta-tomografia 20 minutos e o tempo porta-agulha 83 minutos. Após 180 dias do tratamento, o resultado foi:

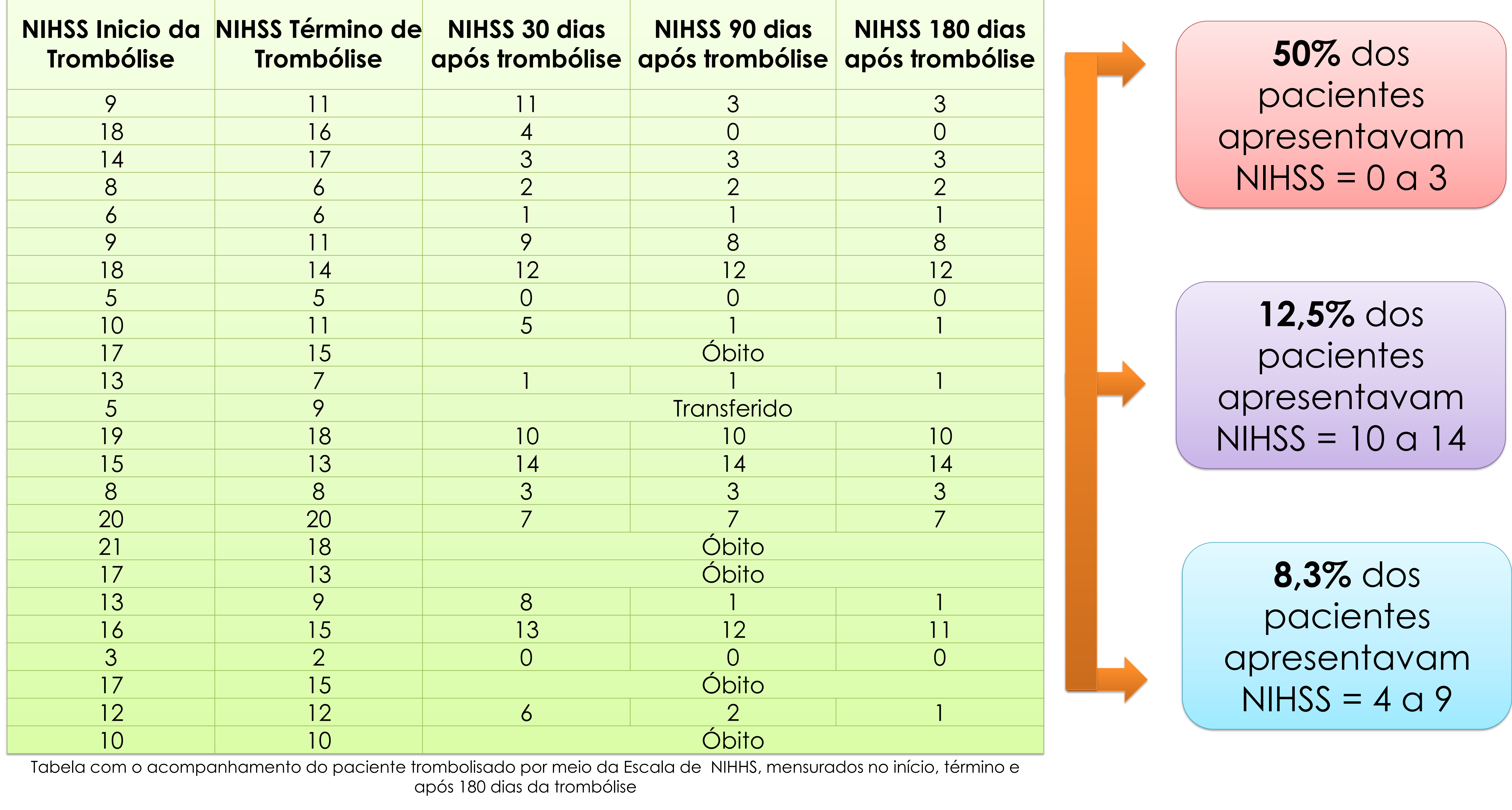

Um paciente foi transferido após receber o tratamento, sendo descontinuado o acompanhamento. A taxa de mortalidade foi de $21 \%$.

Conclusão: Verificamos a importância da LC no atendimento para o paciente com AVE, pois $50 \%$ dos pacientes submetidos a trombólise endovenosa após 180 dias do tratamento apresentavam nenhum ou o mínimo de déficit neurológico, permitindo o retorno ao cotidiano normal. Quanto aos demais pacientes, todos apresentaram melhora de sintomas em comparativo com o início do quadro de $A V E$, porém necessitam de auxílio para realizar suas atividades.

REFERÊNCIAS: (1) Teixeira RA; Silva LD; Ferreira V. Tratamento trombolítico no Acidente Vascular Cerebral Isquêmico. Revista Neurociências. São Paulo, v.12, n.1, 2004. (2) Trevisan CM; Marcon CLV; Cavalheiro BR; Melo LP; Campos TF. Aspectos clínicos relevantes de pacientes com acidente vascular cerebral em emergência hospitalar: implicações para o serviço público de saúde. Rev. Ciênc. Méd. Biol., Salvador, v.14, n.2, p. 171-176, mai./ago. 2015. 